\title{
Removal of NO by carbon-based catalytic reduction bed loaded with Mn induced by dielectric barrier discharge at low temperature
}

\author{
Fan Gao', Xingpeng Jin ${ }^{1}$, Guicheng Wang ${ }^{2}$ Luying Sun ${ }^{1}$, Yujie Tan ${ }^{1}$, Renxi Zhang ${ }^{1 \dagger}$, Weixuan \\ Zhao $^{3 \dagger}$, Jianyuan Hou ${ }^{1}$, Ruina Zhang ${ }^{4}$
}

\author{
${ }^{1}$ Shanghai Key Laboratory of Atmospheric Particle Pollution and Prevention (LAP $\left.{ }^{3}\right)$, Institute of Environmental Science, Fudan \\ University, Shanghai 200433, People's Republic of China \\ ${ }^{2}$ Institute of Developmental Biology and Molecular Medicine, and School of Life Sciences Fudan University, 220 Handan Rd., \\ Shanghai 200433, China \\ ${ }^{3}$ Skshu Paint Co., Ltd., Putian 351100, PR China \\ ${ }^{4}$ Shanghai Institute for Design \& Research on Environmental Engineering, Shanghai 200232, China
}

Received October 08,2021

Revised December 08, 2021

Accepted January 05, 2022

\begin{abstract}
The current paper reports on a newly developed DBD-Mn/FCRB hybrid system to explore the removal of $\mathrm{NO}_{\mathrm{x}}$ by reduction without adding reducing gas at low temperature (below $80^{\circ} \mathrm{C}$ ). This technology was established with a fixed carbon-based reduction catalytic reduction bed loaded with manganese (Mn/FCRB) induced by dielectric barrier discharge (DBD). The NO conversion and $\mathrm{N}_{2}$ selectivity in the new hybrid system reached $90.9 \%$ and $79.9 \%$ respectively under $8 \%$ oxygen content, 1,200 J/L specific input energy (SIE), which were all higher than in the single DBD and DBD-FCRB systems, respectively. The Mn/FCRB was further characterized before and after activation by SEM, XRD and XPS. The possible reaction pathways of denitration were proposed through three processes based on the experimental results: direct denitration of active carbon atoms excited by plasma, reduction by adsorptive $\mathrm{C}(\mathrm{N})$ and $\mathrm{C}(\mathrm{O})$ complexes on the FCRB surface, and the reaction of nitrogen oxides with by-product $\mathrm{CO}$. In addition, the results also showed that the new in-situ reduction denitration system had strong oxygen shock resistance and water resistance.
\end{abstract}

Keywords: Dielectric barrier discharge, Fixed carbon-based reduction bed, Mn-based catalysts, Nitric oxide

(C) $\$$ This is an Open Access article distributed under the terms
of the Creative Commons Attribution Non-Commercial Li-
cense (http://creativecommons.org/licenses/by-nc/3.0/) duction in any medium, provided the original work is properly cited.
Corresponding Author

E-mail: zrx@fudan.edu.cn; 15210740032@fudan.edu.cn Tel: +86-13604041266 Fax: +021-65642293

Tel: +86-15201721351 Fax: +0355-3383872

ORCID: 0000-0002-7867-4932 (R.Z); 0000-0002-0289-3514 (W.Z) 


\section{Introduction}

2 With the increasing awareness of environmental protection, more and more attention has been

3 paid to the atmospheric environment. Nitrogen oxides $\left(\mathrm{NO}_{\mathrm{x}}\right)$ are considered the primary

4 pollutants worldwide which come from combustion processes of coal-based fossil fuel power

5 generation, fuel vehicles and other incineration processes [1-3]. They are responsible for such

6 environmental problems as photochemical smog $[4,5]$, acid rain [6], combining with volatile

7 organic compounds to produce ozone [7]. Further to the above, they cause many health problems

8 including damage to the heart and lungs [8-10]. Nowadays, $\mathrm{NO}_{\mathrm{x}}$ are mainly removed by selective

9 catalytic reduction (SCR) owing to its high removal efficiency [11, 12]. But this technology

10 features a relatively narrow operation temperature window $\left(300-400^{\circ} \mathrm{C}\right)$ which means that the

11 de-NOx unit is placed upstream of the dedusting and desulfuration units, leading to activity

12 declining and shorter service life of the catalysts [13]. What's more, the SCR technology

13 continues to raise the worries for the leakage or escape of the reducing gas (for example,

14 ammonia slip) [14]. Therefore, an environment-friendly de- $\mathrm{NO}_{\mathrm{x}}$ technology at low temperature

15 has long been a question of great interest.

16 The non-thermal plasma (NTP) has been reported as a promising and effective

17 technology for removing $\mathrm{NO}_{\mathrm{x}}$ which generally consists of highly reactive species including

18 electrons, ions, radicals, excited and neutral species $[15,16]$ that all can interact with each other

19 and contribute to the decompose hazardous air pollutants. NTP is used to selectively transfer

20 energy to the electrons, thus avoiding the energy consumption necessary for the heating of the

21 entire gas flow and the strong temperature dependence of the catalytic activity can be overcome

22 by the addition of the plasma technology [17,18]. Dielectric barrier discharge (DBD) has been 
1 demonstrated as the superior mode for the generation of NTP $[19,20]$. Nevertheless, NO

2 removal by plasma was mainly attributed to oxidation [21-25], hence ammonia [26, 27] and

3 hydrocarbon gas as $\mathrm{CH}_{4}[28,29], \mathrm{C}_{3} \mathrm{H}_{6}$ [30], $\mathrm{C}_{3} \mathrm{H}_{8}$ [31], $\mathrm{C}_{7} \mathrm{H}_{16}[32]$ and $\mathrm{C}_{8} \mathrm{H}_{18}$ [33] are used as

4 reducing gases in many previous studies. However, there is the limitations of gas leakage are yet

5 to be overcome.

Carbonaceous materials can reduce $\mathrm{NO}_{\mathrm{x}}$ as an adsorbent and undergo heterogeneous gas-

7 solid reactions with $\mathrm{NO}$ to form $\mathrm{N}_{2}$ [34]. Moreover, plasma-enhanced catalysis can lead to

8 synergistic effects $[35,36]$ and induce the $\mathrm{C}-\mathrm{NO}$ reaction which requires a very high temperature

9 (above $900^{\circ} \mathrm{C}$ ) in general $[37,38]$. However, due to the high affinity of carbon to oxygen $[39,40]$,

10 carbon will preferentially react with residual $\mathrm{O}_{2}$, resulting in low $\mathrm{N}_{2}$ selectivity and high carbon

11 combustion [41]. Manganese, as one of the transition metals, is often used as the active

12 component of catalysts because of its abundant variable state including $\mathrm{MnO}, \mathrm{MnO}_{2}, \mathrm{Mn}_{2} \mathrm{O}_{3}$,

$13 \mathrm{Mn}_{3} \mathrm{O}_{4}, \mathrm{Mn}_{5} \mathrm{O}_{8}$ [42-44], and many studies have proved the important contribution of $\mathrm{Mn}$ as

14 catalysts for $\mathrm{NO}_{\mathrm{x}}$ reduction by carbon materials [42, 43, 45-47]. Therefore, the method used

15 fixed carbon-based reduction beds (FCRB) loaded with Mn induced by DBD is expected to

16 become a new denitrification technology at low temperature which has low carbon consumption

17 and high $\mathrm{N}_{2}$ selectivity. However, there is no research on this technology, and the specific

18 reaction pathways for the system have not been figured out owing to the rapid, complex and

19 undetectable reaction process.

20 The current paper reports on a new developed system utilized to investigate the

21 performance of the DBD induced $\mathrm{Mn} / \mathrm{FCRB}$ (DBD-Mn/FCRB) de- $\mathrm{NO}_{\mathrm{x}}$ technology at low

22 temperature (below $80^{\circ} \mathrm{C}$ ), compared with the single DBD system and the DBD-FCRB hybrid 
1 system. And the pore structure and surface micro-characteristic parameters of the Mn/FCRB

2 before and after activation were also measured to explore the specific reaction mechanism of 3 denitration. In addition, the influence of oxygen content and humidity on the denitration effect of

4 the new system has been further investigated.

5

\section{2. Material and Methods}

\section{$7 \quad$ 2.1. Experimental Setup}

8 In this paper, industrial coal-based activated carbon was purchased from Heatton Environmental

9 Tech Ltd. (Shanghai, China), and the performance parameters of the FCRB are shown in Table

10 S1. After grinding and mechanically sieving the original sample, the activated carbon with a

11 particle size distribution of 0.6 1 $\mathrm{mm}$ (18-30 mesh) was obtained, which was washed 3 times

12 with deionized water to remove the original impurities and dried at $105^{\circ} \mathrm{C}$ for $12 \mathrm{~h}$.

13 The Mn/FCRB catalyst was introduced by excess-solution impregnation using manganese 14 acetate $\left(\left(\mathrm{CH}_{3} \mathrm{COO}\right)_{2} \mathrm{Mn}\right)$ of appropriate concentration to obtain around $5 \mathrm{wt} \%$ metal content $(10$ $15 \mathrm{ml}$ of solution/gram of FCRB), and the mixed solution was placed on a magnetic stirrer for $3 \mathrm{~h}$.

16 The FCRB-solution mixtures were dried and placed in an oven for $10 \mathrm{~h}$ at $110^{\circ} \mathrm{C}$, then the dried 17 product was put into a muffle furnace and calcined at $450^{\circ} \mathrm{C}$ for $3 \mathrm{~h}$.

The denitration reaction device is shown in Fig. 1, which mainly includes the gas supply 19 system, reaction system, and outlet gas analysis and detection system. The experiment was carried out in a dielectric barrier discharge reactor with a coaxial cylinder structure, including an

21 inner tube (quartz glass, $11 \mathrm{~mm}$ outer diameter, tube length $275 \mathrm{~mm}$, wall thickness $1 \mathrm{~mm}$ ), outer 22 tube (stainless steel, inner diameter $21 \mathrm{~mm}$ ), inner electrode (with a stainless steel sheet wrapped 
1 around the inner wall of the inner tube, thickness $0.3 \mathrm{~mm}$, length $165 \mathrm{~mm}$ ) and the circulating

2 water outer tube (stainless steel, inner diameter $5 \mathrm{~mm}$, tube length $172 \mathrm{~mm}$ ). The DBD was

3 generated using an alternating current power supply and the specific input energy (SIE) (Eq. (1))

4 ranges from 600 to 1,200 J/L. A $200 \mathrm{MHz}$ digital phosphor oscilloscope (TDS2024B, Tektronix,

5 USA) was used to analyze power. A probe thermometer (Testo 925, Testo SE \& Co. KGaA,

6 Germany) was used to measure the temperature of the FCRB right after each reaction power off,

7 and an infrared thermometer (Testo 830-T1, Testo SE \& Co. KGaA, Germany) was used to

8 measure the temperature outside the wall of the reaction zone during each reaction process. The

9 inner tube was hollow for sucking cold air, and the external circulating water ensured that the

10 temperature in the reaction zone was below $80{ }^{\circ} \mathrm{C}$. The humidity was adjusted by an ultrasonic

11 atomizer (402AI, yuwell group, China) to control the $\mathrm{H}_{2} \mathrm{O}$ content in the carrier gas (Argon),

12 therefore the feed gas had different humidity. The humidity was measured by a psychrometer

13 (Testo 605-H1, Testo SE \& Co. KGaA, Germany) before the feed gas entered the DBD reactor. 


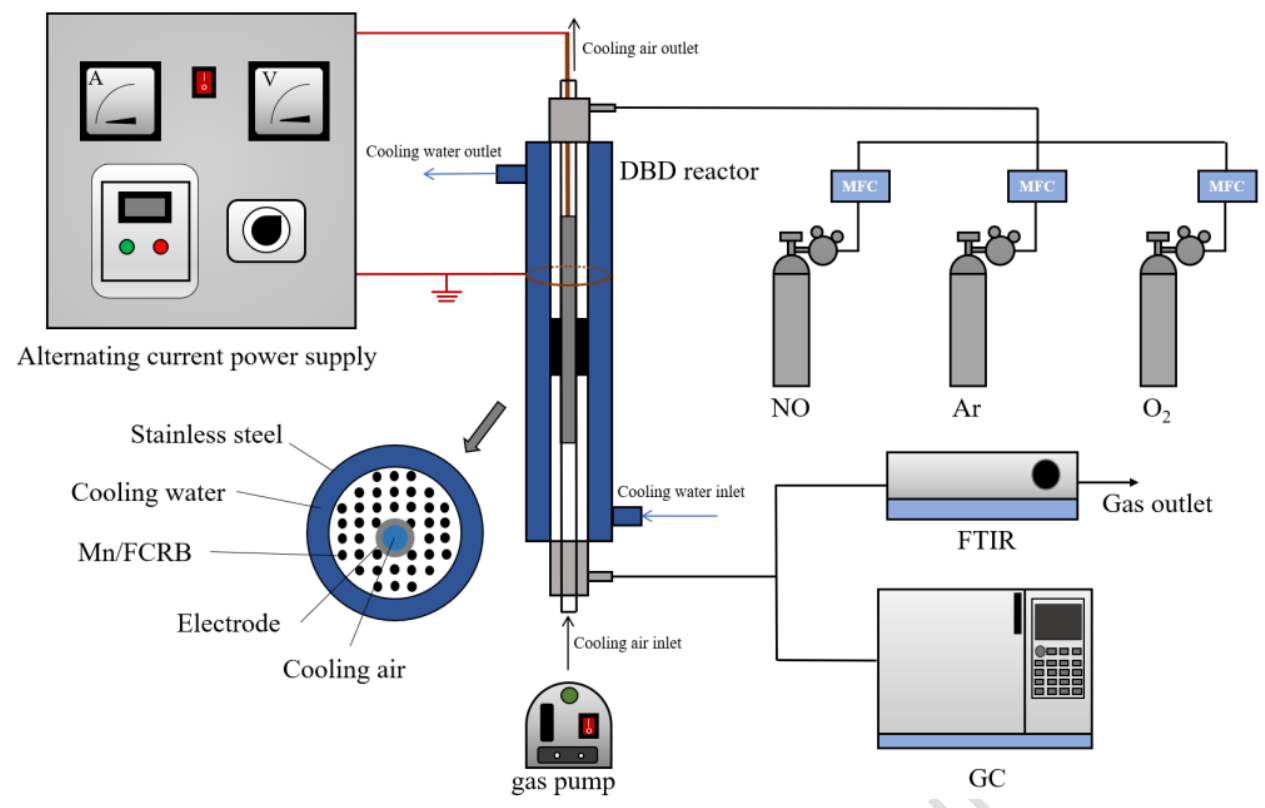

2 Fig. 1. Schematic of the DBD-Mn/FCRB hybrid system.

$4 \quad$ 2.2. Experimental Methods

$5300 \mathrm{mg}$ of FCRB or Mn/FCRB was loaded on the quartz wool in the DBD discharge zone,

6 purged with Argon (Ar) at room temperature for 10 minutes to drive out the remaining impurities,

7 and then the test gases were let into the reactor. To avoid the influence of $\mathrm{NO}_{\mathrm{x}}$ produced by

8 oxidation of $\mathrm{N}_{2}$ on composition analysis of outlet gas, Ar was selected as the carrier gas which

9 was conducive to the discussion of $\mathrm{NO}_{\mathrm{x}}$ removal mechanism and reaction paths in the system.

$10 \mathrm{NO}$, Ar and $\mathrm{O}_{2}$ came from the gas tanks containing high purity gases. The inlet flow rate was

11 independently controlled by the Horiba Stec-4400 mass flow controller to ensure that the

12 concentration of $\mathrm{NO}$ was $428 \mathrm{mg} / \mathrm{m}^{3}$, and the $\mathrm{O}_{2}$ concentration was controlled at $0-16 \%$. The

13 feed gas flow rate was $2 \mathrm{~L} / \mathrm{min}$, the space velocity (Eq. (2)) in the DBD reaction zone was

$142,895.2 \mathrm{~h}^{-1}$, and the residence time in the reactor was $2.1 \mathrm{~s}$. After the $\mathrm{NO}_{\mathrm{x}}$ monitor (Testo 340, 
1 Testo SE \& Co. KGaA, Germany) detected that the $\mathrm{NO}_{\mathrm{x}}$ concentration in the outlet gas was

2 stable, the plasma power supply was switched on to start the discharge and the FTIR

3 spectrometer (FTIR 850, Guangdong Co., China, $0.5 \mathrm{~cm}^{-1}$ ) was used to quantitatively analyze the

$4 \quad \mathrm{NO}_{\mathrm{x}}$ components of the outlet gas, and the data were all collected 15 min after the reaction began

5 when the outlet $\mathrm{NO}_{\mathrm{x}}$ concentration had stabilized. The gas chromatography (GC-9860, Jump

6 Instrument, China) was used to detect the $\mathrm{CO}$ and $\mathrm{CO}_{2}$ content in the outlet gas.

7 The space velocity, removal performance and $\mathrm{N}_{2}$ selectivity of the DBD-Mn/FCRB

8 hybrid system were defined as follows:

9

12 Where $\mathrm{NO}_{\text {in }}, \mathrm{NO}_{\text {out }}, \mathrm{NO}_{2}$ in and $\mathrm{NO}_{2}$ out are the inlet and outlet concentrations of $\mathrm{NO}$ and $\mathrm{NO}_{2}$,

13 respectively, ppm. $\mathrm{NO}_{2}$ in all came from the $\mathrm{NO}$ oxidation in presence of $\mathrm{O}_{2}$ in the intake pipe.

$$
\mathrm{N}_{2} \text { selectivity }(\%)=\frac{\left(\mathrm{NO}_{\text {in }}+\mathrm{NO}_{2} \text { in }\right)-\left(\mathrm{NO}_{\text {out }}+\mathrm{NO}_{2 \text { out }}\right)}{\mathrm{NO}_{\text {in }}+\mathrm{NO}_{2} \text { in }} \times 100 \%
$$

15

16

17

18

19

20

$$
\text { space velocity }\left(h^{-1}\right)=\frac{Q_{\text {inlet flow }\left(m^{3} / h\right)}}{V_{F C R B}\left(m^{3}\right)}
$$


1 experiments were carried out with $\mathrm{Al} \mathrm{K} \alpha$ radiation $(1486.6 \mathrm{eV})$. Binding energies were calibrated 2 using the $\mathrm{C} 1$ s peak $(284.6 \mathrm{eV})$ as a reference.

$4 \quad$ 3. Results and Discussion

5 3.1. De- $\mathrm{NO}_{x}$ Performances
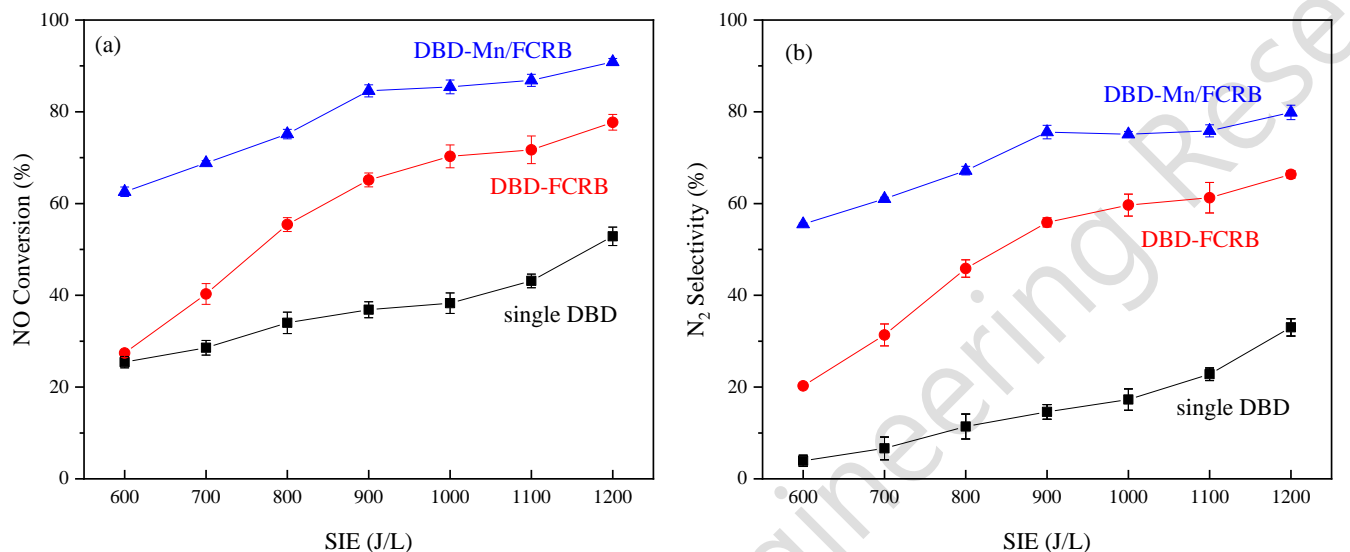

6

Fig. 2. (a) NO conversion and (b) $\mathrm{N}_{2}$ selectivity under different SIE over the single DBD, DBDFCRB and DBD-Mn/FCRB systems $\left(428 \mathrm{mg} / \mathrm{m}^{3} \mathrm{NO}, 8 \% \mathrm{O}_{2}\right.$, Ar used as the balance gas).

As shown in Fig. 2, when the plasma SIE increased from 600 to $1,200 \mathrm{~J} / \mathrm{L}$, the NO conversion and $\mathrm{N}_{2}$ selectivity improved with the enhancement of the discharge energy in the single DBD, DBD-FCRB and DBD-Mn/FCRB systems. The NO conversion and $\mathrm{N}_{2}$ selectivity in the single DBD system were only 52.9 and $33.0 \%$, respectively under $8 \%$ oxygen, $1,200 \mathrm{~J} / \mathrm{L}$ SIE, while those in the DBD-FCRB system reached 77.7 and $66.4 \%$, respectively, and the highest $\mathrm{NO}$ conversion and $\mathrm{N}_{2}$ selectivity were increased to 90.9 and $79.9 \%$ in the DBD$\mathrm{Mn} / \mathrm{FCRB}$ system, respectively. Therefore, Mn loading can serve reduction denitrification as the dominant denitration path, and significantly improve its denitrification performance and $\mathrm{N}_{2}$ selectivity. Moreover, compared with the $\mathrm{NH}_{3}-\mathrm{SCR}$ system using carbon-based loaded $\mathrm{Mn}$ 
1 catalyst without NTP activation at low temperature, the NO conversion of these technologies is

2 usually less than $80 \%$, and the temperature is about $160 \sim 250{ }^{\circ} \mathrm{C}[48,49]$. And the $\mathrm{NO}$ conversion

3 is generally in the range of $50 \sim 75 \%$ when the temperature is as high as $150 \sim 350{ }^{\circ} \mathrm{C}$ in the NTP-

4 stimulated SCR denitrification technology with different catalysts at low temperature [50, 51].

5 In the single DBD system, plasma collided with $\mathrm{NO}, \mathrm{O}_{2}$, and other molecules through

6 electrons, thereby generating free radicals such as $\mathrm{N}$ and $\mathrm{O} \cdot$ that can oxidize or reduce $\mathrm{NO}$ (Eq.

7 (3) (6)). In the DBD-FCRB and DBD-Mn/FCRB systems, the reactions described above also

8 occurred, in addition, the carbon activated by DBD may react with NO (Eq. (7) and (8)). As a

9 result, the excellent $\mathrm{N}_{2}$ selectivity was performed through the reduction denitration path.

10

11

12

13

14

15

16

\section{3.2. Mn/FCRB Characterization}

18

\subsubsection{SEM results}

$$
\begin{gathered}
\mathrm{e}+\mathrm{NO} \rightarrow \mathrm{N}+\mathrm{O} \cdot \mathrm{e} \\
\mathrm{e}+\mathrm{O}_{2} \rightarrow 2 \mathrm{O} \cdot+\mathrm{e} \\
\mathrm{NO}+\mathrm{O} \cdot \mathrm{NO}_{2} \\
\mathrm{NO}+\mathrm{N} \rightarrow \mathrm{N}_{2}+\mathrm{O} . \\
\mathrm{C}+\mathrm{NO}_{2} \rightarrow \mathrm{NO}+\mathrm{CO}\left(\text { or } \mathrm{CO}_{2}\right)
\end{gathered}
$$$$
\mathrm{C}+\mathrm{NO} \rightarrow \mathrm{N}_{2}+\mathrm{CO}\left(\text { or } \mathrm{CO}_{2}\right)
$$ 

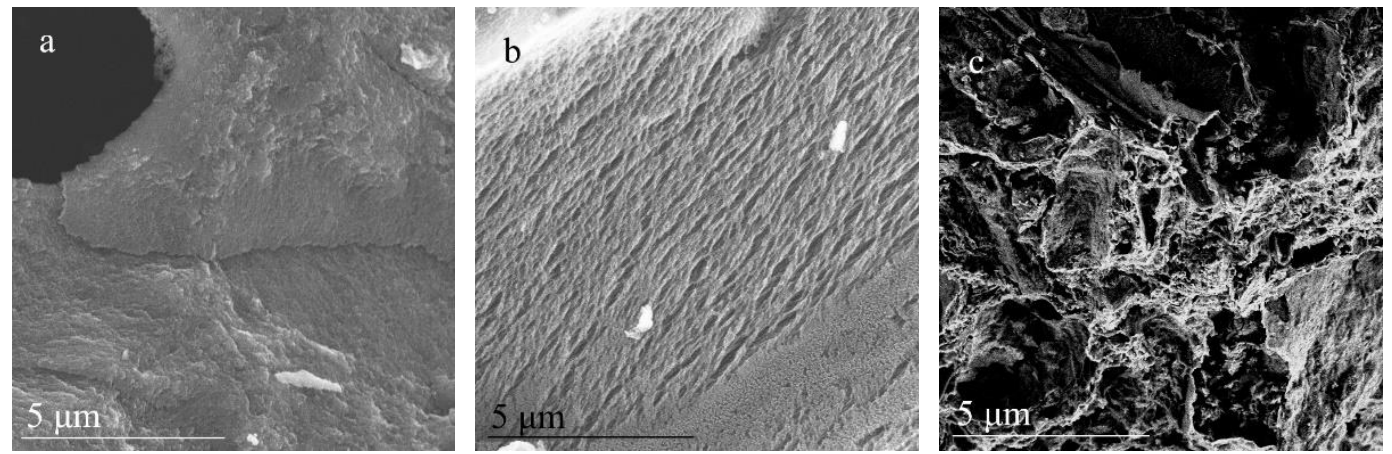

Fig. 3. SEM images of FCRB: (a) blank FCRB, (b) the FCRB activated by DBD, and (c) the $\mathrm{Mn} / \mathrm{FCRB}$ activated by DBD.

Figure 3 shows the SEM images of the original blank FCRB (B-FCRB), the FCRB and Mn/FCRB activated by DBD (A-FCRB and A-Mn/FCRB). After the plasma activation, there were obvious traces of etching both on the surfaces of A-FCRB and A-Mn/FCRB. These findings suggest that the surface of the FCRB and Mn/FCRB was excited by DBD to produce short-lived active carbon atoms. The previous researches have shown that through the highenergy gas species penetrating the surface of the material to a depth of several nanometers, the plasma can cause the surface of the carbon material to break the covalent bond, ion impact, etc.

12 so that the surface carbon atoms are removed by various reactions[52, 53]. Thereby, the active carbon atoms excited by plasma etching can probably reduce NO and cause the Eq. (7) and Eq.

14 (8) reactions.

17 As shown in Fig. S1, the XRD pattern shows peaks that are identified as $\mathrm{SiO}_{2}$. There was no significant characteristic diffraction peak containing $\mathrm{Mn}$ in the sample B-Mn/FCRB, indicating that the active component mainly existed in an amorphous state, and $\mathrm{SiO}_{2}$ is decomposed by 
1 calcination in the preparation process. Higher dispersion can inhibit the formation of crystal

2 clusters, effectively reduce the particle size of manganese oxide on the catalyst surface,

3 improved the dispersion degree of active component $\mathrm{MnO}_{\mathrm{x}}$ on the FCRB and increased lattice

4 defects of the catalyst [54]. The surface distribution uniformity of Mn/FCRB decreased after

5 DBD activation, and there are obvious characteristic peaks of $\mathrm{MnO}_{\mathrm{x}}$ in the sample $\mathrm{A}-\mathrm{Mn} / \mathrm{FCRB}$.

6

7 3.2.4. XPS results
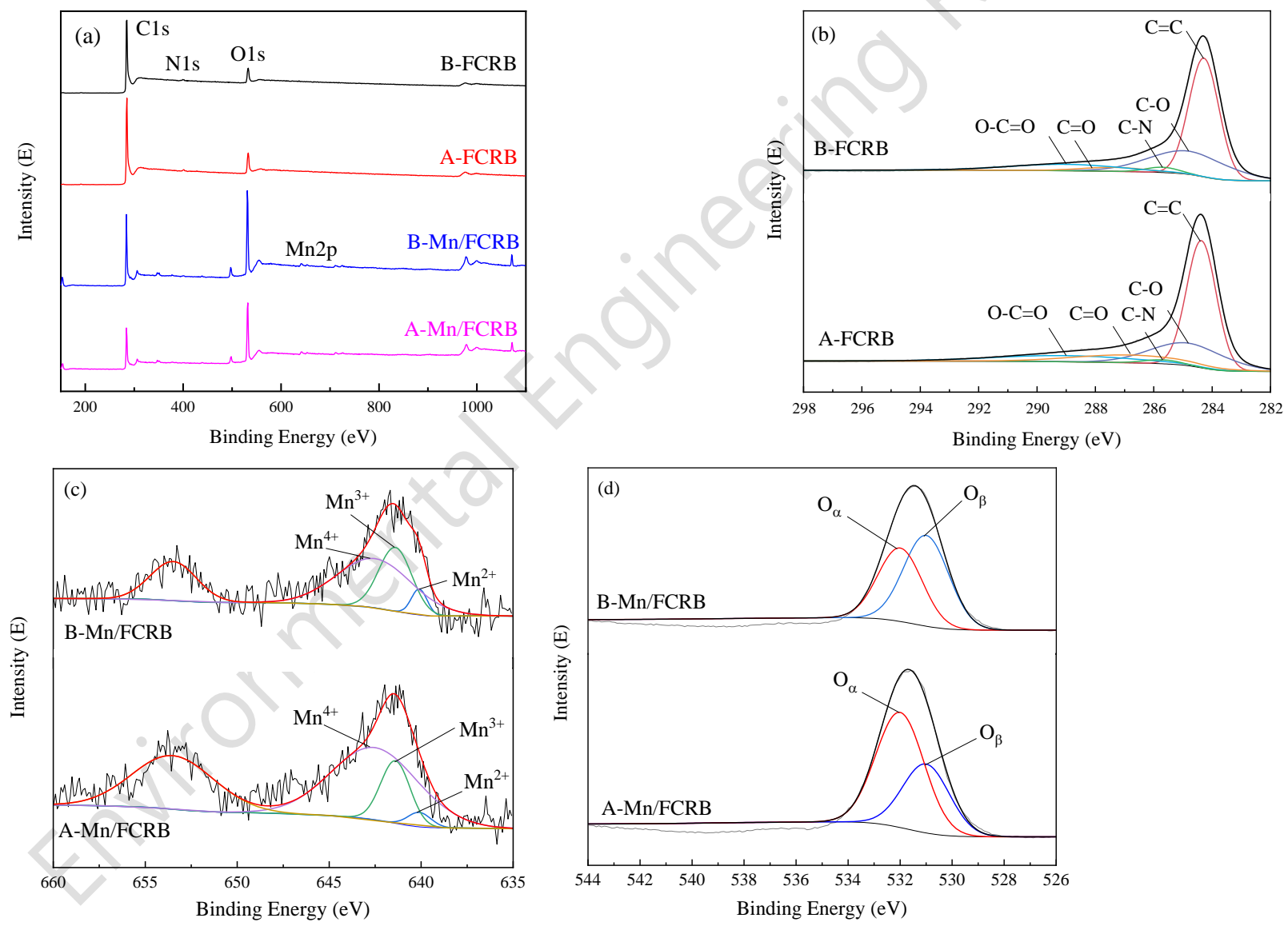

Fig. 4. (a) XPS survey spectra of FCRBs, (b) XPS spectrum of C1s peak of B-FCRB and AFCRB, and XPS spectrum of (c) Mn2p peak and (d) O1s peak of B-Mn/FCRB and A-Mn/FCRB.

12 
1 Table 1. The Relative Content of Various Elements and Functional Groups Based on the XPS

2 Spectra

\begin{tabular}{|c|c|c|c|c|c|}
\hline \multirow[b]{2}{*}{ Category } & & \multicolumn{4}{|c|}{ Sample } \\
\hline & & B-FCRB & A-FCRB & $\begin{array}{c}\text { B- } \\
\text { Mn/FCRB } \\
\end{array}$ & $\begin{array}{c}\text { A- } \\
\text { Mn/FCRB } \\
\end{array}$ \\
\hline $\mathrm{C} / \mathrm{O}$ & & 8.4 & 7.5 & 1.7 & 1.6 \\
\hline $\mathrm{C} / \mathrm{N}$ & & 44.7 & 51.6 & 47.7 & 51.9 \\
\hline \multirow{5}{*}{$\begin{array}{l}\text { Functional } \\
\text { groups relative } \\
\text { Content } \\
(\%)\end{array}$} & $\mathrm{C}=\mathrm{C} 284.3 \mathrm{eV}$ & 54.4 & 51.2 & - & - \\
\hline & $\mathrm{C}-\mathrm{O} 284.8 \mathrm{eV}$ & 28.0 & 23.0 & & - \\
\hline & C-N $285.7 \mathrm{eV}$ & 2.7 & 2.0 & - & - \\
\hline & $\mathrm{C}=\mathrm{O} 287.1 \mathrm{eV}$ & 4.0 & 11.9 & 2 & - \\
\hline & $\mathrm{O}-\mathrm{C}=\mathrm{O} 289.0 \mathrm{eV}$ & 10.9 & 11.9 & - & - \\
\hline \multicolumn{2}{|c|}{$\mathrm{S}_{\mathrm{Mn}^{4+}} / \mathrm{S}_{\mathrm{Mn}^{3+}} / \mathrm{S}_{\mathrm{Mn}^{2+}}$} & - & & $9.2 / 5.2 / 1$ & 18.9/5.5/1 \\
\hline \multicolumn{2}{|l|}{$\overline{\mathrm{S}_{\mathrm{O}_{\alpha}}} / \mathrm{S}_{\mathrm{O}_{\beta}}$} & - & & 0.8 & 1.7 \\
\hline
\end{tabular}

3

4 Fig. 4(a) shows the surface elements of B-FCRB, A-FCRB, B-Mn/FCRB and A-Mn/FCRB were

5 mainly carbon, nitrogen, and oxygen. The relative contents of the elements and functional groups

6 are listed in Table 1. As can be seen from the table, the $\mathrm{C} 1 \mathrm{~s} / \mathrm{O} 1 \mathrm{~s}$ atomic ratio has decreased from

$78.4(\mathrm{~B}-\mathrm{FCRB})$ and $1.7(\mathrm{~B}-\mathrm{Mn} / \mathrm{FCRB})$ to $7.5(\mathrm{~A}-\mathrm{FCRB})$ and $1.6(\mathrm{~A}-\mathrm{Mn} / \mathrm{FCRB})$ respectively,

8 indicating that oxygen functional groups (OFGs) have increased after the plasma activation. The

$9 \mathrm{C} 1 \mathrm{~s} / \mathrm{N} 1 \mathrm{~s}$ atomic ratio has increased from 44.7 (B-FCRB) and 47.7 (B-Mn/FCRB) to 51.6 (A-

$10 \mathrm{FCRB})$ and $51.9(\mathrm{~A}-\mathrm{Mn} / \mathrm{FCRB})$ respectively after plasma activation, showing that nitrogen

11 functional groups (NFGs) were consumed during the denitration process.

12 The C1s peaks of B-FCRB and A-FCRB were divided into 5 peaks respectively, as 13 shown in Fig. 4(b). As can be seen from Table 1, the intensity of $\mathrm{C}=\mathrm{C}$ groups reduced after DBD 14 activation from 54.5 to $51.2 \%$. It is known that the energy of positive, negative ions and 15 electrons present in the plasma is sufficient to break chemical bonds on the outer surface of a 
1 material, and the radicals formed in the plasma process were first formed in the $\pi$ bonds $(\mathrm{C}=\mathrm{C})$

2 on the surface of carbonaceous materials because they are active and the most susceptible to

3 plasma attack [55-57]. Therefore, the carbon-carbon network was disrupted, and new $\mathrm{C}(\mathrm{O})$ and

$4 \mathrm{C}(\mathrm{N})$ groups were generated on the surfaces of Mn/FCRB by DBD activation as shown by Eq.

5 (9) (11) (where $C^{*}$ means the active site on the Mn-FCRB surface). The results show that the

6 total content of $\mathrm{C}(\mathrm{O})$ complexes including $\mathrm{C}-\mathrm{O}$ (e.g., epoxy, hydroxyl), $\mathrm{C}=\mathrm{O}$ (e.g., carbonyl,

7 quinone), and $\mathrm{C}(\mathrm{O}) \mathrm{O}$ (e.g., carboxyl, lactone) was increased from 42.9 to $46.8 \%$. However, the

8 content of $\mathrm{C}-\mathrm{O}$ and $\mathrm{C}-\mathrm{N}$ was decreased after the denitration process. This result may be

9 explained by the fact that these two complexes are more unstable and more likely to participate

10 in the reactions and be consumed. emphasized [58-61], and the same considerations may be indicated in the C-NO induced by DBD. $\mathrm{C}(\mathrm{N})$ can react with newly adsorbed NO near the surface of Mn-FCRB to produce $\mathrm{N}_{2}$ in a 17 gas-solid heterogeneous phase, as shown by Eq. (12). Moreover, $\mathrm{C}(\mathrm{N})$ can also produce $\mathrm{N}_{2}$ 18 through the solid-phase polymerization reaction of Eq. (13), which also has the effect of reducing 19 denitrification and will re-release carbon active sites. On the other hand, $\mathrm{C}(\mathrm{O})$ complexes were 20 beneficial to the electron transfer on the carbon surface. Moreover, $\mathrm{C}(\mathrm{O})$ has high reactivity that 21 can directly reduce NO and the reduction reaction between $\mathrm{C}(\mathrm{O})$ and NO is shown in Eq. (14). 
1 As NO is reduced to $\mathrm{N}_{2}$, the active sites of carbon resume activity again, and it goes back and 2 forth. the catalyst. The oxygen vacancies are known to play an important role in the adsorption and

11 dissociation of oxygen molecules, leading to the generation of highly active electrophilic $\mathrm{O}_{2}$ [65].

12 In O1s XPS spectra (Fig. 4(d)) of B-Mn/FCRB and A-Mn/FCRB, the peak at $531 \mathrm{eV}$ is assigned 13 to lattice oxygen $\left(\mathrm{O}_{\beta}\right)$, and the peak in B-Mn/FCRB and A-Mn/FCRB occur at $532 \mathrm{eV}$, which 14 can be assigned to surface adsorbed oxygen species $\left(\mathrm{O}_{\alpha}\right)$, resulting from the adsorption of 15 gaseous $\mathrm{O}_{2}$ into oxygen vacancies [66]. The $\mathrm{O}_{\alpha} / \mathrm{O}_{\beta}$ ratio increased after DBD activation (Table 1), 16 in good agreement with the de-NOx activities, which also indicated that DBD activation 17 increased oxygen vacancies that promoted superior low-temperature reducibility. 

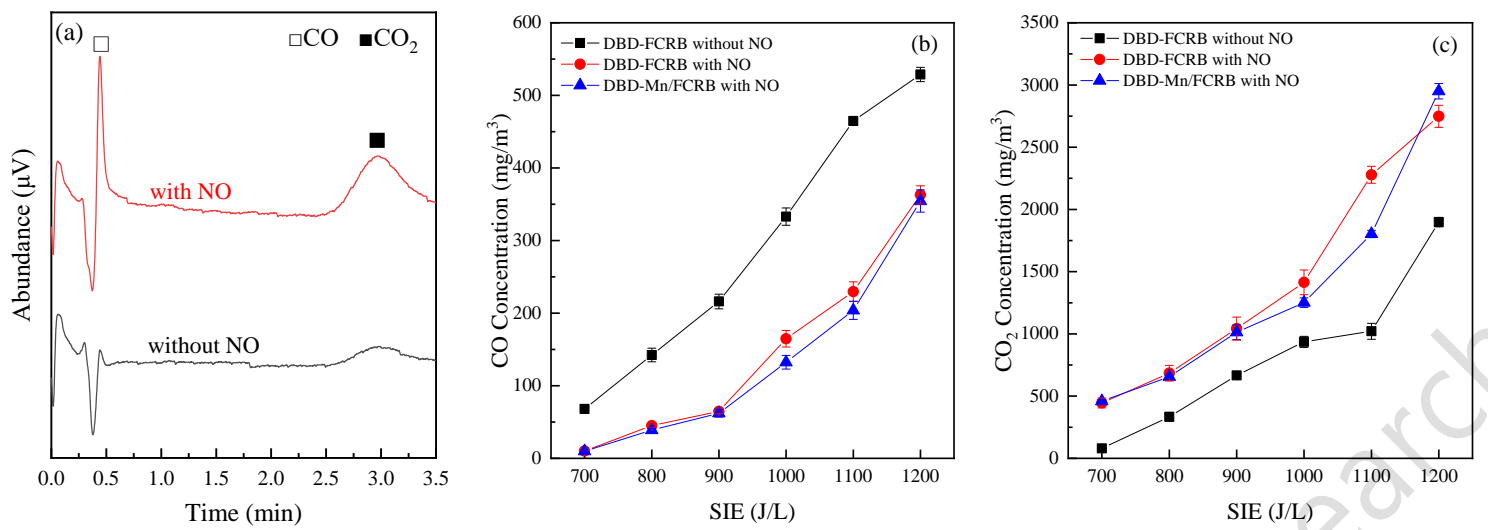

Fig. 5. (a) GC spectrum observed with and without $428 \mathrm{mg} / \mathrm{m}^{3} \mathrm{NO}$ in $\mathrm{Ar}$ and $0 \% \mathrm{O}_{2}$ condition over the DBD-FCRB system ( $\mathrm{SIE}=1,000 \mathrm{~J} / \mathrm{L}$ ), and (b) $\mathrm{CO}$ and (c) $\mathrm{CO}_{2}$ concentration under different SIE in $\mathrm{Ar}$ and $8 \% \mathrm{O}_{2}$ over the DBD-FCRB and DBD-Mn/FCRB system with and without $428 \mathrm{mg} / \mathrm{m}^{3} \mathrm{NO}$.

As shown in Fig. 5(a), after the injection of NO, CO outlet concentration has increased from 2.2 to $15.4 \mathrm{mg} / \mathrm{m}^{3}$, and the $\mathrm{CO}_{2}$ outlet concentration has also increased from 52 to 126 $\mathrm{mg} / \mathrm{m}^{3}$ in the DBD-FCRB system in the absence of oxygen. This can lead to the conclusion that the amount of $\mathrm{CO}_{\mathrm{x}}$ produced has increased significantly due to the input of $\mathrm{NO}$, which not only proved that $\mathrm{C}$ will react with $\mathrm{NO}$ (because $\mathrm{O}$ of $\mathrm{NO}$ was the only source of $\mathrm{O}$ in $\mathrm{CO}_{\mathrm{x}}$ in the absence of oxygen), also proved the existence of $\mathrm{CO}$ products in the reaction zone just as the presumed Eq. (8). An implication of this result is the possibility that there should be a gas-phase reduction reaction Eq. (15) in the DBD-FCRB system.

$$
2 \mathrm{CO}+2 \mathrm{NO} \rightarrow \mathrm{N}_{2}+2 \mathrm{CO}_{2}
$$

To further prove the role of the $\mathrm{CO}-\mathrm{NO}$ reaction, the $\mathrm{CO}$ concentration measurement under the $8 \%$ oxygen condition was carried out. As shown in figure $5(\mathrm{~b}, \mathrm{c})$, the amount of $\mathrm{CO}$ and $\mathrm{CO}_{2}$ produced increased with the SIE increased, but the $\mathrm{CO}$ output in the presence of NO was less than in the absence of $\mathrm{NO}$ and $\mathrm{CO}_{2}$ output presented an opposite trend. If $\mathrm{NO}$ was only 
1 reduced and removed by $\mathrm{C}(\mathrm{O})$ and $\mathrm{C}(\mathrm{N})$ complexes or active carbon atoms, then due to the

2 reactions of Eq. (7), (8), and (12) happening, theoretically the CO content should increase in the

3 presence of $\mathrm{NO}$, which was contrary to the experimental results. The results indicated that $\mathrm{CO}$

4 was consumed by the NO-CO reaction in the DBD-Mn/FCRB system. What's more, when NO

5 was present in the gas intake, the effect of Mn catalyst was to significantly increase the reactivity

6 both by increasing the number of reaction sites via the catalyst dispersion and reducing the

7 activation energy and by increasing $\mathrm{CO}_{2}$ production[67]. The latter can also be proved by the

8 average $\mathrm{CO}_{2} / \mathrm{CO}$ ratio that increased from 16.9 to 17.7 compared between the DBD-FCRB

9 system and DBD-Mn/FCRB system, indicating that less carbon was consumed per molecule of

10 NO reduced in the DBD-Mn/FCRB system.

11

\subsection{Effects of $\mathrm{O}_{2}$ and $\mathrm{H}_{2} \mathrm{O}$}
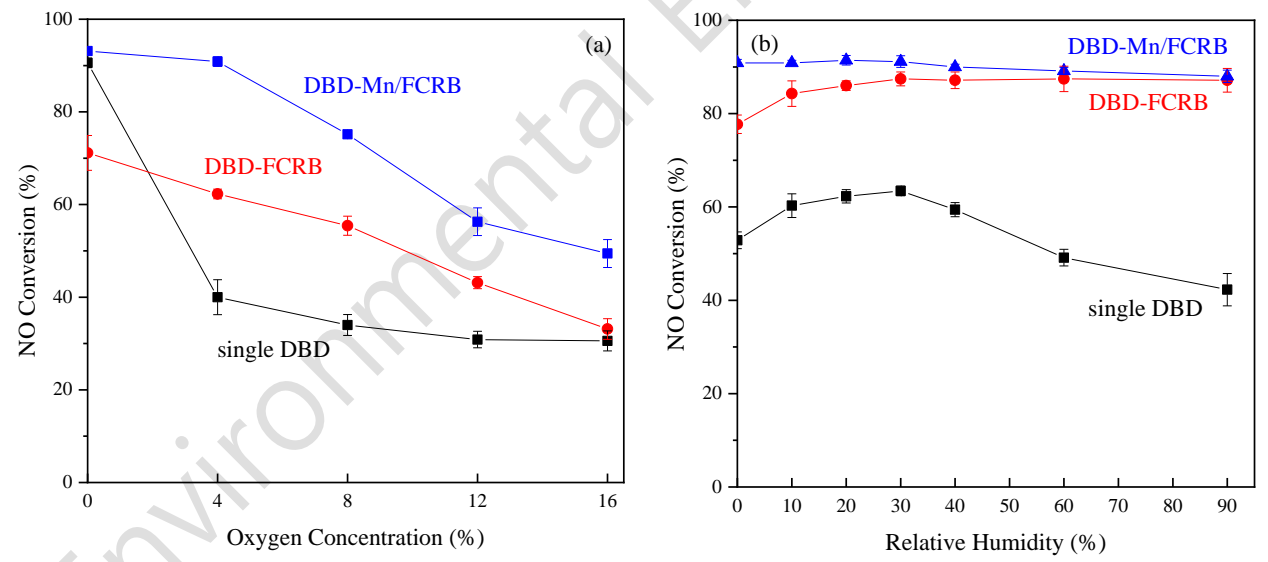

Fig. 6. Effects of (a) $\mathrm{O}_{2}$ concentration and (b) $\mathrm{H}_{2} \mathrm{O}$ on $\mathrm{NO}$ conversion over the single DBD, DBD-FCRB, and DBD-Mn/FCRB systems $\left(428 \mathrm{mg} / \mathrm{m}^{3} \mathrm{NO}\right.$, Ar used as the balance gas, $\mathrm{SIE}=$ $800 \mathrm{~J} / \mathrm{L}$ ) 
1 It is very necessary to explore the role of oxygen to understand the mechanism of this reduction

2 system. It can be seen from Fig. 6(a) that when the SIE was $800 \mathrm{~J} / \mathrm{L}$ and the oxygen content

3 increased from 0 to $16 \%$, the NO conversion decreased in the three systems. The large input of

4 oxygen molecules will cause the excitation and decomposition of NO to be weakened and

5 promote the occurrence of oxidation reactions (Eq. (16) (18)), which increased the concentration

6 of $\mathrm{NO}$ and $\mathrm{NO}_{2}$. However, the overall performance of the DBD-Mn/FCRB system was better

7 than that of the single DBD system, especially in the low and medium oxygen zone (4 8\%). For

8 the DBD-FCRB and DBD-Mn/FCRB systems, although the reaction atmosphere was

9 undoubtedly an oxidizing atmosphere, there was a reducing system on the surface of FCRB.

10 FCRB can absorb $\mathrm{O}_{2}$ and $\mathrm{O}$. species (Eq. (11)) so that the carbon can act as a buffer for oxygen

11 shock. Therefore, the DBD-FCRB and DBD-Mn/FCRB systems reduced the sensitivity of the

12 system to oxygen concentration. With the further increase of oxygen content, the adsorption

13 active sites on the surface of FCRB gradually approached saturation, its buffering effect on

14 oxygen-containing species was relatively insignificant, but it still had a relatively good 15 denitration effect in the DBD-Mn/FCRB system.

$$
\begin{aligned}
& \mathrm{N}+\mathrm{O} \cdot \rightarrow \mathrm{NO} \\
& \mathrm{NO}+\mathrm{O} \cdot \rightarrow \mathrm{NO}_{2} \\
& \mathrm{NO}_{2}+\mathrm{O} \cdot \rightarrow \mathrm{NO}+\mathrm{O}_{2}
\end{aligned}
$$

Exploring the influence of humidity on denitration capacity is helpful to the practical application of the technology. As shown in Fig. 6(b), no matter in what relative humidity conditions, the NO conversion of the DBD-FCRB system was better than that of the single DBD system, and DBDMn/FCRB was slightly better than the DBD-FCRB system. In the single DBD system, the NO 
1 conversion increased from 52.9 to $63.4 \%$ then decreased to $42.3 \%$. The increase was caused by

$2 \mathrm{H} \cdot, \cdot \mathrm{OH}$ and $\mathrm{HO}_{2} \cdot$ active groups generated from water molecules under the bombardment of

3 plasma. As a strong oxidizing radical, $\mathrm{HO}_{2}$. will further oxidize $\mathrm{NO}$ to $\mathrm{NO}_{2}$ (Eq. (19) (21)). And

4 the phenomenon was also found in this study that $\mathrm{NO}$ decreased and $\mathrm{NO}_{2}$ increased which also

5 further confirmed this reaction mechanism. The NO conversion in the single DBD system

6 decreased because water molecules acted as a "quencher" gradually, which consumes some of

7 the active species to produce $\mathrm{H}^{-}, \mathrm{OH}^{-}$and a few $\mathrm{O}^{-}$anions by dissociative electron attachment to

$8 \mathrm{H}_{2} \mathrm{O}$ molecules[68], so the number of active species participating in the NO reduction reaction

9 decreased. However, the denitration capacity was stable at high humidity in the DBD/FCRB

10 system and the NO conversion was $87.1 \%$ when the relative humidity was $90 \%$, as a

11 consequence of the increased moisture absorption of FCRB as humidity increases [69], and the

12 content of water molecules in the reaction zone was relatively stable. However, although the

13 presence of water vapor did not affect the crystal form, particle size and specific surface area of

14 the Mn-based catalysts, it can compete with $\mathrm{NO}$ to adsorb at the active center on the catalyst

15 surface, resulting in a decrease in the number of available active centers in the reaction process,

16 thus inhibiting the activity of the catalyst [70]. Therefore, the NO conversion of the DBD-

$17 \mathrm{Mn} / \mathrm{FCRB}$ system decreased slightly with the increase of humidity overall and was similar to the

18 DBD-FCRB system in the high humidity area with the lowest $88.0 \%$ of the NO conversion.

$$
\mathrm{H}_{2} \mathrm{O}+\mathrm{e} \rightarrow \mathrm{H} \cdot+\cdot \mathrm{OH}+\mathrm{e}
$$

$$
\mathrm{H} \cdot+\mathrm{O}_{2} \rightarrow \mathrm{HO}_{2} \cdot
$$

$$
\mathrm{NO}+\mathrm{HO}_{2} \cdot \rightarrow \mathrm{NO}_{2}+\cdot \mathrm{OH}
$$




\section{4. DBD-Mn/FCRB System Reaction Mechanism}

2 In the denitration process of the DBD-Mn/FCRB system, the first step is that $\mathrm{NO}$ and $\mathrm{O}_{2}$

3 molecules are impacted by high-energy particles in the plasma atmosphere to produce a large

4 number of active radical groups such as $\mathrm{N}$ and $\mathrm{O} \cdot$, and the surface of Mn/FCRB is also etched

5 and excited by the plasma at the same time. Afterward, these gaseous high-energy intermediate

6 particles will undergo adsorption and various chemical reactions with the surface of FCRB.

7 In summary, the main reduction denitrification reaction processes of the DBD-Mn/FCRB

8 system are shown in Fig. 7. As mentioned earlier, the DBD-Mn/FCRB system is mainly

9 reductive denitrification. The first reductive denitrification path is the direct participation of gas-

10 solid heterogeneous reaction, that is, the Mn/FCRB surface is excited by the strong

11 bombardment of plasma to produce active carbon atoms which can directly reduce NO and

12 produce $\mathrm{CO}$ or $\mathrm{CO}_{2}$, as shown in Fig. 7(a). In addition, plasma can also excite more carbon

13 active sites $\mathrm{C}^{*}$, thereby promoting chemical adsorption. The second reaction mechanism is to use

14 the adsorbed $\mathrm{C}(\mathrm{O})$ and $\mathrm{C}(\mathrm{N})$ complexes to generate solid-phase and gas-solid heterogeneous

15 reactions to reduction denitrification, as shown in Fig. 7(b) (d). The third path is to use the CO

16 produced by the first two reaction pathways and the desorption of the oxygen complex $\mathrm{C}(\mathrm{O})$ on

17 the Mn/FCRB surface for CO-NO gas-phase reaction, as shown in Fig. 7(e). 


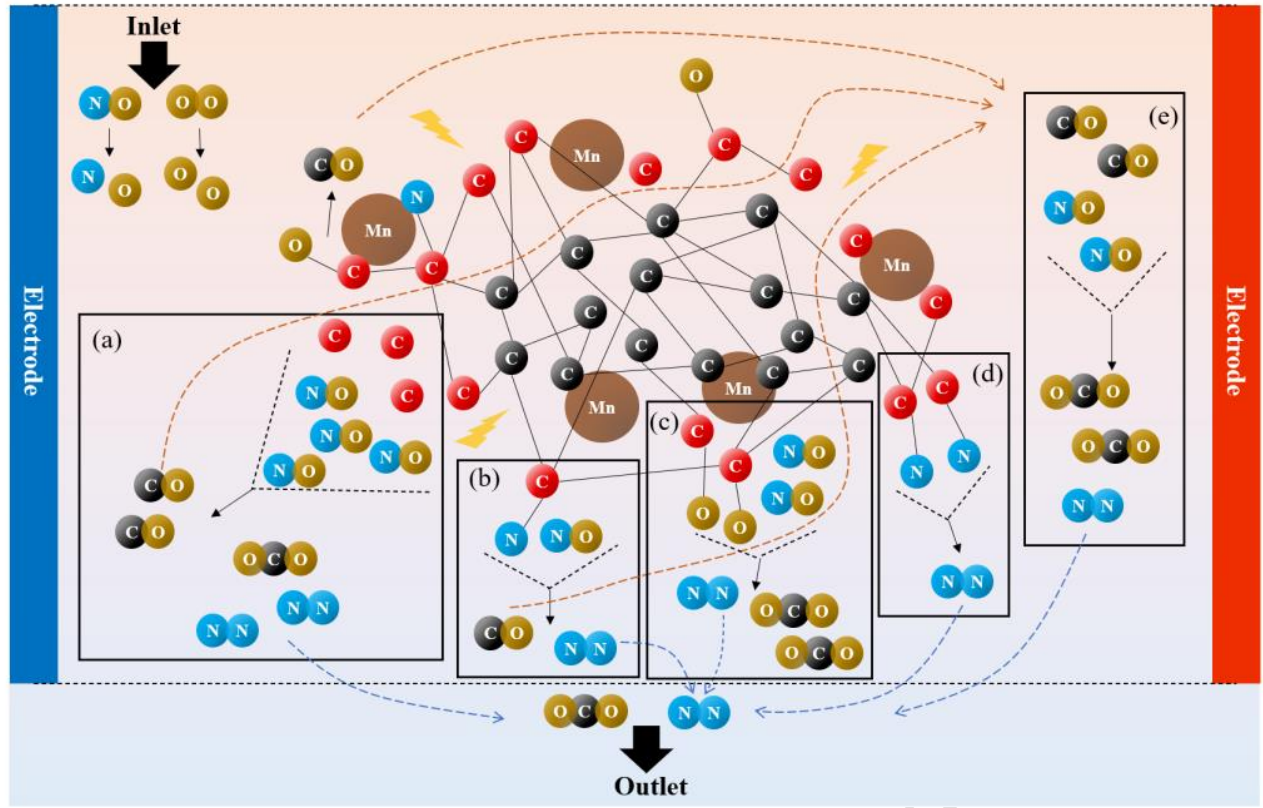

Fig. 7. Reduction denitrification reaction processes of DBD-Mn/FCRB system.

\section{Conclusions}

A new hybrid system DBD-Mn/FCRB was established to explore the removal of $\mathrm{NO}_{\mathrm{x}}$ and the reaction mechanism by reduction without adding reducing gas at low temperature (below $80^{\circ} \mathrm{C}$ ) for the first time. The results presented herein provide definite evidence of the role of Mn/FCRB in promoting the reduction de-NOx performance of the NTP at low temperature. The higher NO conversion and $\mathrm{N}_{2}$ selectivity, and lower carbon consumption in the DBD-Mn/FCRB hybrid system showed the best NO reduction capacity. The mechanisms of the removal of $\mathrm{NO}_{\mathrm{x}}$ in the new system were also proposed through three processes: direct denitration of active carbon atoms excited by plasma, reduction by adsorptive $\mathrm{C}(\mathrm{N})$ and $\mathrm{C}(\mathrm{O})$ complexes on the carbon surface, and the reaction of nitrogen oxides with by-product CO. In addition, the new in-situ catalytic reduction denitration system had good oxygen shock resistance and water resistance. 


\section{Acknowledgments}

2 This research was funded by the technology innovation and level promotion project supported by

3 Shanghai State-owned assets supervision and Administration Commission (No. 2018001) and

4 the science and technology innovation action project supported by the science and technology

5 commission of Shanghai Municipality (No. 18DZ1202605) and the Special research project on

6 causes and control technology of air pollution (No. 2017YFC0212905).

7

\section{Author Contributions}

9 F. G. (M.A. student) conducted all the experiments and wrote the manuscript. X.P.J. (M.A. 10 student) assisted in the development of methodology. G.C.W. (Professor) revised the manuscript. 11 L.Y.S. (M.A. student) assisted in conducting experiments. Y.J.T. (M.A. student) assisted in 12 conducting experiments. R.X.Z. (Professor) assisted in formulation of overarching research goals 13 and revised the manuscript. W.X.Z. (Ph.D.) assisted in the manuscript writing. J.Y.H. (Professor) 14 assisted in the development of methodology and data curation. R.N.Z. (Ph.D.) revised the 15 manuscript.

16

\section{References}

18 [1] Skalska K, Miller JS, Ledakowicz S. Trends in $\mathrm{NO}_{\mathrm{x}}$ abatement: A review. Sci. Total. 19 Environ. 2010;408:3976-3989.

20 [2] Seitzinger SP, Phillips L. Nitrogen stewardship in the Anthropocene. Science $21 \quad 2017 ; 357: 350$. 
1 [3] Janssens TVW, Vennestrøm PNR. A molecular dance to cleaner air. Science $2 \quad 2017 ; 357: 866$.

3 [4] Bang HQ, Nguyen HD, Vu K, et al. Photochemical smog modelling using the air

4 pollution chemical transport model (TAPM-CTM) in Ho Chi Minh city, Vietnam. Environ.

5 Model. Assess. 2019;24:295-310.

6 [5] Lewis AC. The changing face of urban air pollution. Science 2018;359:744.

7 [6] Wang $\mathrm{C}$, Wang W, Sardans J, et al. Effect of simulated acid rain on $\mathrm{CO}_{2}, \mathrm{CH}_{4}$ and $\mathrm{N}_{2} \mathrm{O}$

8 fluxes and rice productivity in a subtropical Chinese paddy field. Environ. Pollut. $9 \quad 2018 ; 243: 1196-1205$.

10 [7] McDonald BC, De Gouw JA, Gilman JB, et al. Volatile chemical products emerging as 11 largest petrochemical source of urban organic emissions. Science 2018;359:760.

12 [8] Lelieveld J, Evans JS, Fnais M, et al. The contribution of outdoor air pollution sources to 13 premature mortality on a global scale. Nature 2015;525:367-371.

14 [9] Zhao CN, Xu Z, Wu GC, et al. Emerging role of air pollution in autoimmune diseases. 15 Autoimmun. Rev. 2019;18:607-614.

16 [10] Schraufnagel DE, Balmes JR, Cowl CT, et al. Air pollution and noncommunicable 17 diseases: A review by the Forum of International Respiratory Societies' Environmental 18 Committee, Part 2: Air pollution and organ systems. Chest. 2019;155:417-426.

19 [11] Brüggemann TC, Keil FJ. Theoretical investigation of the mechanism of the selective 20 catalytic reduction of nitric oxide with ammonia on H-form zeolites. J. Phys. Chem. C. $21 \quad 2008 ; 112: 17378-17387$. 
1 [12] Tan LA, Guo YA, Liu ZB, et al. An investigation on the catalytic characteristic of $\mathrm{NO}_{\mathrm{x}}$

2 reduction in SCR systems. J. Taiwan Inst. Chem. E. 2019;99:53-59.

3 [13] Liang Q, $\mathrm{Li} \mathrm{J}, \mathrm{He} \mathrm{H}$, et al. Effects of $\mathrm{SO}_{2}$ on the low temperature selective catalytic

4 reduction of $\mathrm{NO}$ by $\mathrm{NH}_{3}$ over $\mathrm{CeO}_{2}-\mathrm{V}_{2} \mathrm{O}_{5}-\mathrm{WO}_{3} / \mathrm{TiO}_{2}$ catalysts. Front. Environ. Sci. Eng. $5 \quad 2017 ; 11: 150-156$.

6 [14] Dong L, Fan Y, Ling W, et al. Effect of Ce/Y addition on low-temperature SCR activity 7 and $\mathrm{SO}_{2}$ and $\mathrm{H}_{2} \mathrm{O}$ resistance of $\mathrm{MnO}_{\mathrm{x}} / \mathrm{ZrO}_{2} / \mathrm{MWCNTs}$ catalysts. Catalysts 2017;7:181.

8 [15] Oda T, Kato T, Takahashi $\mathrm{T}$, et al. Nitric oxide decomposition in air by using non9 thermal plasma processing-with additives and catalyst. J. Electrostat. 1997;42:151-157.

10 [16] Feng X, Liu H, He C, et al. Synergistic effects and mechanism of a non-thermal plasma 11 catalysis system in volatile organic compound removal: a review. Catal. Sci. Technol. $12 \quad 2018 ; 8: 936-954$.

13 [17] Palma V, Cortese M, Renda S, et al. A Review about the Recent Advances in Selected 14 NonThermal Plasma Assisted Solid-Gas Phase Chemical Processes. Nanomaterials $15 \quad 2020 ; 10: 1596$.

16 [18] Von Keudell A, Volker S V D G. Foundations of low-temperature plasma physics - an 17 introduction[J]. Plasma Sources Sci. Technol. 2017;26:113001.

18 [19] Bai M, Zhang Z, Bai M. Simultaneous desulfurization and denitrification of flue gas by $19 . \mathrm{OH}$ radicals produced from $\mathrm{O}_{2}{ }^{+}$and water vapor in a duct. Environ. Sci. Technol. $20 \quad 2012 ; 46: 10161-10168$.

21 [20] Kogelschatz U. Dielectric-barrier discharges: their history, discharge physics, and 22 industrial applications. Plasma Chem. Plasma P. 2003;23:1-46. 
1 [21] Zhu AM, Sun Q, Niu JH, et al. Conversion of $\mathrm{NO}$ in $\mathrm{NO} / \mathrm{N}_{2}, \mathrm{NO} / \mathrm{O}_{2} / \mathrm{N}_{2}, \mathrm{NO} / \mathrm{C}_{2} \mathrm{H}_{4} / \mathrm{N}_{2}$ and

$2 \mathrm{NO} / \mathrm{C}_{2} \mathrm{H}_{4} / \mathrm{O}_{2} / \mathrm{N}_{2}$ systems by dielectric barrier discharge plasmas. Plasma Chem. Plasma P. $3 \quad 2005 ; 25: 371-386$.

4 [22] McLarnon CR, Penetrante BM. Effect of gas composition on the $\mathrm{NO}_{\mathrm{x}}$ conversion 5 chemistry in a plasma. SAE transactions. 1998;107:886-897.

6 [23] Stefanovic I, Bibinov NK, Deryugin AA, et al. Kinetics of ozone and nitric oxides in 7 dielectric barrier discharges in $\mathrm{O}_{2} / \mathrm{NO}_{\mathrm{x}}$ and $\mathrm{N}_{2} / \mathrm{O}_{2} / \mathrm{NO}_{\mathrm{x}}$ mixtures. Plasma Sources Sci. Technol. $8 \quad 2001 ; 10: 406-416$.

9 [24] Yan K, Kanazawa S, Ohkubo T, et al. Oxidation and reduction processes during $\mathrm{NO}_{\mathrm{x}}$ 10 removal with corona-induced nonthermal plasma. Plasma Chem. Plasma P. 1999;19:421-443.

11 [25] Malik MA, Kolb JF, Sun Y, et al. Comparative study of NO removal in surface-plasma 12 and volume-plasma reactors based on pulsed corona discharges. J. Hazard. Mater. $13 \quad 2011 ; 197: 220-228$.

14 [26] Zhu T, Zhang $\mathrm{X}$, Niu W, et al. Selective catalytic reduction of NO by $\mathrm{NH}_{3}$ using a 15 combination of non-thermal plasma and Mn-Cu/ZSM5 catalyst. Catalysts 2020;10:1044.

16 [27] Jiang $\mathrm{B}$, Zhao S, Wang Y, et al. Plasma-enhanced low temperature $\mathrm{NH}_{3}-\mathrm{SCR}$ of $\mathrm{NO}_{\mathrm{x}}$ 17 over a Cu-Mn/SAPO-34 catalyst under oxygen-rich conditions. Appl. Catal. B. 2021;286:119886. 18 [28] Zhu T, Zhang $\mathrm{X}$, Yi N, et al. $\mathrm{NO}_{\mathrm{x}}$ storage and reduction assisted by non-thermal plasma 19 over $\mathrm{Co} / \mathrm{Pt} / \mathrm{Ba} / \mathrm{Y}-\mathrm{Al}_{2} \mathrm{O}_{3}$ catalyst using $\mathrm{CH}_{4}$ as reductant. Plasma Sci. Technol. 2021;23:025506.

20 [29] Pan H, Guo Y, Jian Y, et al. Synergistic effect of non-thermal plasma on $\mathrm{NO}_{\mathrm{x}}$ reduction 21 by $\mathrm{CH}_{4}$ over an In/H-BEA catalyst at low temperatures. Energ. Fuel. 2015;29:5282-5289. 
1 [30] Wang $\mathrm{X}, \mathrm{Li} \mathrm{Y}$, Chen $\mathrm{W}$, et al. Characteristics of $\mathrm{NO}_{\mathrm{x}}$ removal combining dielectric

2 barrier discharge plasma with selective catalytic reduction by $\mathrm{C}_{3} \mathrm{H}_{6}$. Jpn. J. Appl. Phys. 3 2010;49:086201.

4 [31] Pan $\mathrm{H}$, Qiang Y. Promotion of non-thermal plasma on catalytic reduction of $\mathrm{NO}_{\mathrm{x}}$ by $\mathrm{C}_{3} \mathrm{H}_{8}$

5 Over Co/BEA catalyst at low temperature. Plasma Chem. Plasma Process. 2014;34:811-824.

6 [32] Nguyen DB, Nguyen VT, Heo IJ, et al. Removal of $\mathrm{NO}_{\mathrm{x}}$ by selective catalytic reduction 7 coupled with plasma under temperature fluctuation condition. J. Ind. Eng. Chem. 2019;72:4008407.

9 [33] Stere CE, Adress W, Burch R, et al. Probing a non-thermal plasma activated 10 heterogeneously catalyzed reaction using in situ DRIFTS-MS. Acs Catal. 2015;5:956-964.

11 [34] Gupta $\mathrm{H}$, Benson S A, Fan L, et al. Pilot-Scale Studies of $\mathrm{NO}_{\mathrm{x}}$ Reduction by Activated 12 High-Sodium Lignite Chars: A Demonstration of the CARBONOX Process. Ind. Eng. Chem. 13 Res. 2004;43:5820-5827.

14 [35] Ollegott K, Wirth P, Christian Oberste-Beulmann, et al. Fundamental Properties and 15 Applications of Dielectric Barrier Discharges in Plasma-Catalytic Processes at Atmospheric 16 Pressure. Chemie Ingenieur Technik. 2020;92:1542-1558.

17 [36] T. Blackbeard, V. Demidyuk, S. L. Hill, et al. The Effect of Temperature on the Plasma18 Catalytic Destruction of Propane and Propene: A Comparison with Thermal Catalysis. Plasma 19 Chem. Plasma Process. 2009;29:411.

20 [37] Zhao $\mathrm{W}$, Lian $\mathrm{L}$, Jin $\mathrm{X}$, et al. In situ electron-induced reduction of $\mathrm{NO}_{\mathrm{x}}$ via CNTs 21 activated by DBD at low temperature. Front. Env. Sci. Eng. 2019;14. 
1 [38] Peng M, Zhao R, Xia M, et al. Study on the mechanism of NO removal by plasma-

2 adsorption catalytic process. Fuel 2017;200:290-298.

3 [39] Illán-Gómez MJ, Raymundo-Piñero E, Garcı́a-Garc1 a A, et al. Catalytic $\mathrm{NO}_{\mathrm{x}}$ reduction

4 by carbon supporting metals. Appl. Catal. B. 1999;20:267-275.

5 [40] Illán-Gómez MJ, Salinas-Martínez de Lecea C, Linares-Solano A, et al. Potassium-

6 containing coal chars as catalysts for $\mathrm{NO}_{\mathrm{x}}$ reduction in the presence of oxygen. Energ. Fuel.

$7 \quad 1998 ; 12: 1256-1264$.

8 [41] Illán-Gómez $\mathrm{MJ}$, Brandán $\mathrm{S}$, Linares-Solano $\mathrm{A}$, et al. $\mathrm{NO}_{\mathrm{x}}$ reduction by carbon 9 supporting potassium-bimetallic catalysts. Appl. Catal. B. 2000;25:11-18.

10 [42] Liu C, Shi J, Gao C, et al. Manganese oxide-based catalysts for low-temperature selective 11 catalytic reduction of $\mathrm{NO}_{\mathrm{x}}$ with $\mathrm{NH}_{3}$ : A review. Appl Catal A-Gen. 2016;522:54-69.

12 [43] Raja S, Alphin MS, Sivachandiran L. Promotional effects of modified $\mathrm{TiO}_{2}$ - and carbon13 supported $\mathrm{V}_{2} \mathrm{O}_{5}$ - and $\mathrm{MnO}_{\mathrm{x}}$-based catalysts for the selective catalytic reduction of $\mathrm{NO}_{\mathrm{x}}$ : a review. 14 Catal. Sci. Technol. 2020;10:7795-7813.

15 [44] Han L, Cai S, Gao M, et al. Selective catalytic reduction of $\mathrm{NO}_{\mathrm{x}}$ with $\mathrm{NH}_{3}$ by using novel 16 catalysts: state of the art and future prospects. Chem. Rev. 2019;119:10916-10976.

17 [45] Illán-Gómez MJ, Linares-Solano A, Radovic LR, et al. NO reduction by activated 18 carbons. 7. Some mechanistic aspects of uncatalyzed and catalyzed reaction. Energ. Fuel. $19 \quad 1996 ; 10: 158-168$.

20 [46] Li P, Lu P, Zhai Y, et al. Low temperature SCR of NO with catalysts prepared by 21 modified ACF loading $\mathrm{Mn}$ and Ce: effects of modification method. Environ. Technol. $22 \quad 2015 ; 36: 2390-2400$. 
1 [47] Xu G, Guo X, Cheng X, et al. A review of Mn-based catalysts for low-temperature $\mathrm{NH}_{3}$ -

2 SCR: $\mathrm{NO}_{\mathrm{x}}$ removal and $\mathrm{H}_{2} \mathrm{O} / \mathrm{SO}_{2}$ resistance. Nanoscale 2021;13.

3 [48] Yanli W, ChuanZhang G, Liang Z, et al. $\mathrm{MnO}_{\mathrm{x}}-\mathrm{CeO}_{2} /$ Activated Carbon Honeycomb

4 Catalyst for Selective Catalytic Reduction of $\mathrm{NO}$ with $\mathrm{NH}_{3}$ at Low Temperatures. Ind. Eng.

$5 \quad$ Chem. Res. 2012;51:11667-11673.

6 [49] Lishan W, Bichun H, Yanxia S, et al. Manganese oxides supported on multi-walled carbon

7 nanotubes for selective catalytic reduction of $\mathrm{NO}$ with $\mathrm{NH}_{3}$ : Catalytic activity and

8 characterization. Chem. Eng. J..2012:192:232-241.

9 [50] Cristina E. S, Wameedh A, Robbie B, et al. Ambient Temperature Hydrocarbon Selective

10 Catalytic Reduction of $\mathrm{NO}_{\mathrm{x}}$ Using Atmospheric Pressure Nonthermal Plasma Activation of a

$11 \quad \mathrm{Ag} / \mathrm{Al}_{2} \mathrm{O}_{3}$ Catalyst. ACS Catal. 2014;4:666-673.

12 [51] Nguyen DB, Nguyen VT, Heo IJ, et al. Removal of $\mathrm{NO}_{\mathrm{x}}$ by Selective Catalytic Reduction

13 Coupled with Plasma under Temperature Fluctuation Condition. J. Ind. Eng. Chem. $14 \quad 2019 ; 72: 400-407$.

15 [52] Ölçenoğlu G, Saka C. Surface modification of coal sample with oxygen plasma treatment. 16 Surf. Eng. 2019;36:1-8.

17 [53] Kondratowicz I, Nadolska M, Şahin S, et al. Tailoring properties of reduced graphene 18 oxide by oxygen plasma treatment. Appl. Surf. Sci. 2018;440:651-659.

19 [54] Zhao DS. Evaluation and characterization of catalysts. Beijing: Chemical Industry Press; 20 2011. p. 219-225.

21 [55] Tang S, Lu N, Wang JK, et al. Novel effects of surface modification on activated carbon 22 fibers using a low pressure plasma treatment. J. Phys. Chem. C. 2007;111:1820-1829. 
1 [56] Chen C, Liang B, Ogino A, et al. Oxygen functionalization of multiwall carbon

2 nanotubes by microwave-excited surface-wave plasma treatment. J. Phys. Chem. C. $3 \quad 2009 ; 113: 7659-7665$.

4 [57] Saka C. Overview on the surface functionalization mechanism and determination of 5 surface functional groups of plasma treated carbon nanotubes. Crit. Rev. Anal. Chem. 2018;48:1614.

7 [58] Chambrion P, Orikasa H, Suzuki T, et al. A study of the C-NO reaction by using 8 isotopically labelled C and NO. Fue. 1997;76:493-498.

9 [59] Chambrion P, Kyotani T, Tomita A. Role of N-containing surface species on NO 10 reduction by carbon. Energ. Fuel. 2012;12:416-421.

11 [60] Ulán-Gómez MJ, Linares-Solano A, Radovic LR, et al. NO reduction by activated 12 carbons. Some mechanistic aspects of uncatalyzed and catalyzed reaction. Coal Sci. Technol. $13 \quad 1995 ; 24: 1799-1802$.

14 [61] Smith RN, Swinehart J, Lesnini D. The oxidation of cardon by nitric oxide. J. Phys. 15 Chem.1959;63:544-547.

16 [62] Song C, Guo B, Sun XF, et al. Enrichment and degradation of tetracycline using three17 dimensional graphene/ $\mathrm{MnO}_{2}$ composites. Chem. Eng. J. 2019;358:1139-1146.

18 [63] Zhao X, Niu C, Zhang L, et al. Co-Mn layered double hydroxide as an effective 19 heterogeneous catalyst for degradation of organic dyes by activation of peroxymonosulfate. 20 Chemosphere 2018;204:11-21. 
1 [64] Wu M, Zhan W, Guo Y, et al. An effective Mn-Co mixed oxide catalyst for the solvent-

2 free selective oxidation of cyclohexane with molecular oxygen. Appl. Catal. A General. $3 \quad 2016 ; 523: 97-106$.

4 [65] Ma CY, Mu Z, Li JJ, et al. Mesoporous $\mathrm{Co3O} 4$ and $\mathrm{Au} / \mathrm{Co} 3 \mathrm{O} 4$ catalysts for low5 temperature oxidation of trace ethylene. J. Am. Chem. Soc. 2010;132:2608-2613.

6 [66] An J, Lou J, Meng Q, et al. Non-thermal plasma injection- $\mathrm{CeO}_{2}-\mathrm{WO}_{3} / \mathrm{TiO}_{2}$ catalytic 7 method for high-efficiency oxidation of elemental mercury in coal-fired flue gas. Chem. Eng. J. $8 \quad 2017 ; 325: 708-714$.

9 [67] López D, Calo J. The NO-carbon reaction: the influence of potassium and CO on 10 reactivity and populations of oxygen surface complexes. Energ. Fuel 2007;21:1872-1877.

11 [68] Wang T, Sun BM, Xiao HP, et al. Effect of water vapor on NO removal in a DBD reactor 12 at different temperatures. Plasma Chem. Plasma P. 2013;33:681-690.

13 [69] Shi YR, Jiang ZX, Wu TL, et al. Study on the water vapor adsorption capacities of 14 activated carbons. Chem. Ind. Forest Prod. 1982:2-12.

15 [70] Cai W, Zhao Y, Chen M, et al. The formation of 3D spherical Cr-Ce mixed oxides with 16 roughness surface and their enhanced low-temperature NO oxidation. Chem. Eng. J. $17 \quad 2018 ; 333: 414-422$. 